\title{
Rapid and sensitive detection of Taura syndrome virus using nucleic acid-based amplification
}

\author{
Ping-Hua Teng ${ }^{1,2}$, Chu-Liang Chen ${ }^{2}$, Cheng-Nan $\mathrm{Wu}^{3}$, Sih-Ying $\mathrm{Wu}^{1}$, Bo-Rong $\mathrm{Ou}^{2}$, \\ Pei-Yu Lee (,* $^{3}$ \\ ${ }^{1}$ Farming IntelliGene Technology Corporation, 1-2, Gung-Ye Seventh Road, Tai-Chung Industrial Park, \\ Tai-Chung, 407, Taiwan \\ ${ }^{2}$ Department of Animal Sciences and Biotechnology, Tung-Hai University, Taichung, 407, Taiwan \\ ${ }^{3}$ Graduate Institute of Medical Biotechnology, Central Taiwan University of Sciences and Technology, \\ Tai-Chung, 406, Taiwan
}

\begin{abstract}
Requiring only simple heating devices, isothermal nucleic acid-based amplification (NASBA) is a potential detection platform to be developed for on-site diagnosis of aquaculture pathogens. In this report, an NASBA assay has been developed for the Taura syndrome virus (TSV), one of the most devastating RNA virus pathogens for several penaeid shrimp species. The NASBA amplicons were detected by agarose gel electrophoresis and confirmed by Northern-blotting and dot-blotting analysis, using a biotinylated TSV-specific primer. The sensitivity of the TSV NASBA coupled with dot-blotting detection was approximately 5-fold less sensitive than that of the commercially available RT-nested, PCR-based IQ2000 TSV Detection and Prevention System that was also confirmed to be more sensitive than the RT-PCR-based TSV detection protocol recommended by the OIE (Office International des Epizooties). The specificity of the TSV NASBA reaction was substantiated by the results that RNA of non-target viruses did not generate any signals. Furthermore, a simple colorimetric microtiter plate assay employing TSV-specific capture and detection primers was developed as a simple alternative approach for the detection of NASBA amplicons. Taken together, the combination of the isothermal NASBA and colorimetric solid phase-based assays should allow sensitive, straightforward, and speedy on-site detection of TSV.
\end{abstract}

KEY WORDS: Nucleic acid-based amplification · NASBA · Diagnostics · IQ $2000 \cdot$ Taura syndrome virus

\section{INTRODUCTION}

Taura syndrome virus (TSV) was first reported from Penaeus vannamei in Ecuador in 1992 (Lightner 1995). TSV disease has spread widely via infected broodstock throughout America and Southeast Asia, causing severe economic losses in the shrimp aquaculture industry in the last decade (Brock 1997, Tu et al. 1999, Robles-Sikisaka et al. 2002, Chang et al. 2004). TSV is known to cause high mortality in $P$. vannamei, P. schmitti, and P. seiferus, while sparing P. stylirostris, P. monodon, $P$. japanicus, $P$. duorarum, $P$. chinensis, and P. aztecus (Brock 1997, Overstreet et al. 1997).
TSV infection leads to $60-90 \%$ mortality in $P$. vannamei, the survivors become chronically infected but present no symptoms (Lightner 1996).

TSV, a member of the Dicistroviridae, contains a single-stranded, positive-sense RNA genome that is about $10205 \mathrm{nt}$ long and encodes 2 non-overlapping open reading frames, ORF1 and ORF2 aura syndrome. ORF1 and ORF2 are predicted to encode the nonstructural and structural polyproteins, respectively. Phylogenic analysis based on the nucleotide sequences of CP2 suggested that there are 3 lineages, namely the Americas, Belize, and SE Asia, among the various geographic TSV isolates (Robles-Sikisaka et al. 
2002, Tang \& Lightner 2005). In the CP1 and CP2 regions, low genetic variation (0 to $0.24 \%$ for $\mathrm{CP} 1$ and 0 to 0.35 or 0 to $5.6 \%$ for CP2 nucleotide sequences) was observed among the isolates analyzed. Due to the low-fidelity nature of the RNA-dependent RNA polymerase, new isolates of TSV that are able to replicate freely in a new species, such as the one described by Chang et al. (2004) in Penaeus monodon, are expected to keep emerging.

Sensitive and specific detection of the causative agents is a prerequisite for effective disease prevention and management. Methods developed for TSV detection and characterization include histological analyses, immunoassay, in situ hybridization, reverse transcription-polymerase chain reaction (RT-PCR), and real-time RT-PCR (Lightner 1995, Mari et al. 1998, Nunan et al. 1998, Poulos et al. 1999, Castagna et al. 2004, Tang et al. 2004). Among the methods described above, diagnosis of potential TSV carriers or TSV outbreaks at early stages relies mainly on sensitive and specific platforms, such as the nested and real-time RT-PCR (Romano et al. 1995, Nunan et al. 1998, Tang et al. 2004). However, because of the extensive technical training and expensive equipment involved, these systems have not been widely adopted by farm operators for sensitive and timely on-site diagnosis of TSV.

With the advantage of requiring only simple heating devices, various isothermal nucleic acid amplification methods providing detection sensitivity and specificity comparable to those of PCR have been under intensified development lately (Demidov 2002, Cook 2003, Savan et al. 2005, Zhang et al. 2006). These methods include rolling-circle amplification, loop-mediated isothermal amplification, and nucleic acid-based amplification (NASBA), to name a few. NASBA is a single-step, enzyme-based RNA amplification reaction (Kievits et al. 1991, Deiman et al. 2002), employing 3 enzymes: avian myeloblastosis virus reverse transcriptase (AMV-RT), ribonuclease-H, and T7 RNA polymerase. Two target-specific primers, including one with a 5 '-extension containing the promoter sequence for T7 RNA polymerase, have been designed to amplify the RNA target in exponential kinetics through double-stranded cDNA intermediates. The amplicons are mainly single-stranded RNA, with a polarity opposite that of the target. Since the RNA synthesis step does not require a primer, the maximal yield of the NASBA amplification process could exceed the initial primer levels by at least 1 order of magnitude (Deiman et al. 2002). Being extremely rapid, highly sensitive, and specific (Lanciotti \& Kerst 2001), NASBA is most suitable for amplification of single-stranded RNA targets and has been applied to the detection of RNA viruses, such as human immunodeficiency virus, avian influenza virus, enteroviruses, La Crosse virus, para- influenza virus, and astrovirus, to name just a few (Hibbitts et al. 2003, Tai et al. 2003, Lambert et al. 2005, Yao et al. 2005, Brown 2006).

For aquaculture animal pathogens, NASBA has been reported for the detection of nodaviruses, in which a real-time NASBA was developed (Starkey et al. 2004). Since real-time detection requires expensive apparatus and reagents, such assays are unsuitable for the purpose of simple on-site detection. The ultimate aim of this study was to develop a quick and easy point-ofoperation diagnostic system for pathogens, by coupling isothermal NASBA with solid-phase platforms that are user friendly and affordable for amplicon detection. Therefore, we report here on the development of NASA assays for the detection of TSV, as well as the development of postamplification solid phasebased detection platforms through the use of targetspecific capture and detection probes for NASBA products. The sensitivity and specificity of this system were compared to those of RT-nested PCR.

\section{MATERIALS AND METHODS}

Sample collection. Penaeus vannamei samples were collected from farms in Taiwan. TSV-positive samples were identified by using the IQ2000 TSV Detection and Prevention System (IQ2000 TSV DPS; Farming IntelliGene). Gill-associated virus (GAV)- and infectious myonecrosis virus (IMNV)-positive shrimp samples were kindly provided by Dr. Peter Walker (CSIRO, Australia) and Dr. Donald V. Lightner (University of Arizona, USA), respectively. Yellow head virus (YHV)positive samples were collected from the SE Asian countries.

Nucleic acids. Although TSV appears to be present in the lymphoid organ at the highest levels, it has been shown that pleopod sampling provides sufficient degrees of sensitivity for TSV detection, allowing noninvasive screening of costly broodstock (Tang et al. 2004). RNA was extracted from the pleopods or gills of shrimp samples using the RNA Extraction Kit (Farming IntelliGene), following the protocols provided with the kit. The plasmid constructs, pTSV containing a $350 \mathrm{bp}$ fragment from the TSV VP2 gene region and pGFP containing the green fluorescent protein gene, were purified using the Midi-V100 Ultrapure Plasmid Extraction System (Viogene-Biotek).

Primers and oligonucleotide probes. The sequences of the oligonucleotide primers for the NASBA and the probes for detection are listed in Table 1. The cDNA sequences encoding the TSV capsid proteins of different lineages available in GenBank (AF277378, AF277675, AF406789, AY355309, AY355310, AY355311, AY590471, AY826052, and AY826056) were aligned 
Table 1. Nucleotide sequences of primers and probes used in this study. The T7 promoter sequence is underlined (NASBA: isothermal nucleic acid-based amplification; OIE: Office International des Epizooties)

\begin{tabular}{|lll|}
\hline Primer or probe & Sequence & Function \\
\hline TSVF2 & 5'CATTGTGGCTGTGGAATAA 3' & NASBA primer \\
T7 TSVR2 & 5'AATTCTAATACGACTCACTATAGGGAG & NASBA primer \\
& AAGGAAGCCAATAGAATTAGGT 3' & with T7 promoter \\
TSVF3-biotin & 5'CCTGGCATTGAGATGAACTTGCAGTC & \\
& TGAAGCTCGAGCTA 3' & Detection primer \\
TSVR5 & 5'CTCATATGCGTTGACTTTCGT 3' & Capture primer \\
TSVR4 & AGCTTCAGACTGCAAGTTCATCTCAAT & Hybridization control \\
& & capture primer \\
9195 & 5'TCAATGAGAGCTTGGTCC 3' & OIE RT-PCR primer \\
9992 & 5'AAGTAGACAGCCGCGCTT 3' & OIE RT-PCR primer \\
\hline
\end{tabular}

lowed by inactivation at $94^{\circ} \mathrm{C}$ for 2 min. The subsequent $\mathrm{PCR}$ reaction included 35 cycles of denaturation at $94^{\circ} \mathrm{C}$ for $45 \mathrm{~s}$ and annealing/ extension at $60^{\circ} \mathrm{C}$ for $45 \mathrm{~s}$ and a final extension step at $60^{\circ} \mathrm{C}$ for $7 \mathrm{~min}$; $10 \mu \mathrm{l}$ of the amplified products were analyzed in a $2.0 \%$ agarose gel in $0.5 \times$ TBE (Tris, boric acid, ethylene diamine tetra-acetic acid [EDTA]) and visualized as described above.

NASBA. The NASBA amplicons derived from Primers T7 TSVR2 and TSVF2 were expected to be $209 \mathrm{nt}$ long. Reaction conditions for NASBA were modified slightly from those described by Jean et al.

and compared. Design of the primers was based on conserved sequences within the VP2 gene. A standard BLASTN nucleotide-nucleotide search was performed to confirm the specificity of the designed primers. Primers were purchased from BioBasic (Canada) or synthesized at Farming IntelliGene, and purified through high-affinity purification or gel purification before use. The TSVF3-biotin primer was labeled with biotin at its 3 '-end.

RT-nested PCR. For RT-nested PCR analysis, the IQ2000 TSV, YHV, GAV, and IMNV DPS were adopted for the detection of the corresponding viruses. RNA extracts and standards were diluted in yeast tRNA. Briefly, $2 \mu$ of RNA samples was mixed with $7 \mu$ of First PCR Premix, $0.5 \mu \mathrm{l}$ of RT enzyme, and $0.5 \mu \mathrm{l}$ of Taq DNA polymerase. The cDNA was synthesized at $42^{\circ} \mathrm{C}$ for $30 \mathrm{~min}$, followed by 15 of the first PCR cycles. Subsequently, $14 \mu \mathrm{l}$ of Nested PCR Premix and $1 \mu \mathrm{l}$ of Taq DNA polymerase were added to the first PCR reaction, followed by 30 cycles of PCR. The products were separated by electrophoresis in a $1.5 \%$ agarose gel, stained in ethidium bromide, visualized under UV light, and documented by using the AlphaImager Imaging System (Alpha Innotech).

OIE TSV RT-PCR. The sampling and TSV RT-PCR detection procedures were carried out as described in an OIE (Office International des Epizooties) manual (OIE 2003). Briefly, the GeneAmp EZ rTth RNA PCR Kit (Applied Bioscience) was used for the RT-PCR reactions that include $10 \mu \mathrm{l}$ of the total RNA extracted from tissue and $0.46 \mu \mathrm{M}$ each of Primers 9195 and 9992 (Table 1), which amplify a $231 \mathrm{bp}$ sequence of the TSV genome. The $50 \mu \mathrm{l}$ reaction also contains $300 \mu \mathrm{M}$ each of the dNTPs, $2.5 \mathrm{U}$ of rTth DNA polymerase, $2.5 \mathrm{mM}$ manganese acetate, $5 \mathrm{mM}$ bicine, $11.5 \mathrm{mM}$ potassium acetate, and $8 \%$ (w/v) glycerol, pH 8.2. After overlaying the reaction with $50 \mu$ l of light mineral oil, reverse transcription was carried out at $60^{\circ} \mathrm{C}$ for $30 \mathrm{~min}$, fol- (2002a). Briefly, the NASBA reactions were performed in a final $20 \mu \mathrm{l}$ reaction volume containing $2 \mu \mathrm{l}$ of the extracted RNA, $40 \mathrm{mM}$ Tris- $\mathrm{HCl}(\mathrm{pH}$ 8.5), $15 \mathrm{mM}$ $\mathrm{MgCl}_{2}, 50 \mathrm{mM} \mathrm{KCl}, 15 \%$ (v/v) dimethyl sulfoxide, $5 \mathrm{mM}$ dithiothreitol, $0.5 \mathrm{mM}$ of each deoxyribonucleoside triphosphate, $2 \mathrm{mM}$ of each nucleoside triphosphate, $50 \mu \mathrm{g} \mathrm{ul}^{-1}$ bovine serum albumin, and $0.2 \mu \mathrm{M}$ of each primer. The mixture without enzymes was incubated at $65^{\circ} \mathrm{C}$ for $5 \mathrm{~min}$ and $42^{\circ} \mathrm{C}$ for $5 \mathrm{~min}$ before the addition of $2.5 \mathrm{U}$ of RNase H (USB), $12 \mathrm{U}$ of the RNase inhibitor (Takara), $40 \mathrm{U}$ of the T7 RNA polymerase (USB), and $8 \mathrm{U}$ of AMV-RT (Promega), followed by a designated incubation period at $41^{\circ} \mathrm{C}$. Yeast tRNA (40 $\mathrm{ng} \mathrm{ll}^{-1}$ ) was used to dilute RNA samples, to avoid losses of targets at extremely low concentrations.

Denaturing agarose gel electrophoresis and Northern blotting. NASBA amplicons were denatured in $1 \times$ RNA sample buffer (95\% formamide, $0.5 \mathrm{mM}$ EDTA) at $65^{\circ} \mathrm{C}$ for $2 \mathrm{~min}$, and subsequently resolved in a $1.5 \%$ agarose gel containing 3.7\% formaldehyde. After staining with ethidium bromide, the bands were visualized under UV light and subsequently transferred to Hybond$\mathrm{N}$ membrane (Amersham Biosciences) in 20× SSPE overnight. After 1 wash with $5 \times$ SSPE at room temperature, the membrane was UV cross-linked for 2 min in HL-2000 HybriLinker (UVP) and dried at $63^{\circ} \mathrm{C}$. Hybridization was carried out in Dr. Hyb buffer (DR. Chip) containing $0.025 \mu \mathrm{M}$ biotin-labeled TSP-3 at $63^{\circ} \mathrm{C}$ for $30 \mathrm{~min}$. After 2 washes in $1 \times \mathrm{SSPE}$ at $42^{\circ} \mathrm{C}$, the membrane was rinsed with $0.5 \%(\mathrm{w} / \mathrm{v})$ blocking reagent (Roche Diagnostics) in Buffer I (100 mM Tris-HCl, pH 8.0, $150 \mathrm{mM} \mathrm{NaCl}, 0.3 \%$ [v/v] Tween 20) at room temperature, followed by the addition of strepavidin-alkaline phosphatase conjugate (Promega) diluted 1:2000 in Buffer I containing $0.5 \%(\mathrm{w} / \mathrm{v})$ blocking reagent. The incubation was carried out at room temperature for 10 min. After 1 wash with $1 \times$ SSPE and 1 with Buffer II (100 mM Tris-HCl, pH 9.5, $100 \mathrm{mM} \mathrm{NaCl}, 50 \mathrm{mM}$ 
$\mathrm{MgCl}_{2}$ ), color was developed by the addition of $0.5 \mathrm{mg}$ $\mathrm{ml}^{-1} \mathrm{NBT}$ and BCIP in Buffer II. Color was allowed to develop in the dark for no more than $10 \mathrm{~min}$. And the reaction was stopped by rinsing the membrane with water.

Dot blotting. The NASBA products in $1 \times$ RNA sample buffer and the DNA controls in TE buffer were denatured at $95^{\circ} \mathrm{C}$ for $2 \mathrm{~min}$, diluted in $6 \times \mathrm{SSPE}$ buffer, and spotted on the Hybond-N filter. The subsequent UV cross-linking, hybridization, and detection procedures were carried out as described above for Northern blotting. Different concentrations of the pTSV plasmid DNA were included as positive controls for the detection steps.

Microtiter plate detection of NASVA products. NASBA amplicons were captured by an ampliconspecific primer coated on the wells of the FluoroNunc microtiter plate Module MaxiSorp Surface and detected by a TSV-specific, biotin-labeled primer. Briefly, $0.5 \mathrm{nmol}$ of the capture probes, namely TSVR4 and TSVR5, were immobilized on the well in coating buffer $\left(0.045 \mathrm{M} \mathrm{Na}_{2} \mathrm{CO}_{3} / \mathrm{NaHCO}_{3}\right)$, dried at $63^{\circ} \mathrm{C}$ for $5 \mathrm{~min}$, and subsequently UV cross-linked $(1200 \times$ $100 \mu \mathrm{J} \mathrm{cm}^{-2}$ ). The wells were sequentially washed in Buffer I and water. Then, $5 \mu \mathrm{l}$ of the NASBA products mixed with $45 \mu \mathrm{l}$ of $0.025 \mu \mathrm{M}$ biotin-labeled TSP-3 in the hybridization buffer was added to the wells of the microtiter plate which were coated with capture probe in advance. After 30 min of hybridization at $63^{\circ} \mathrm{C}$, the wells were washed 2 times with $1 \times$ SSPE at room temperature. Subsequently, the wells were blocked with Buffer I containing 0.5\% $(\mathrm{w} / \mathrm{v})$ blocking reagent at room temperature, followed by the addition of strepavidin-alkaline phosphatase conjugate diluted 1:2000 in Buffer I containing $0.5 \% \quad(\mathrm{w} / \mathrm{v})$ blocking reagent at room temperature for $10 \mathrm{~min}$. After 1 wash with $1 \times$ SSPE and 1 with Buffer II, $50 \mu \mathrm{l}$ of $0.5 \mathrm{mg} \mathrm{ml}^{-1} \mathrm{NBT}$ and BCIP in Buffer II was added. Color was allowed to develop in the dark for no more than 10 min before the reaction was stopped by rinsing the wells with water.

\section{RESULTS}

\section{Detection of TSV by NASBA}

The Penaeus vannamei samples collected in Taiwan were first screened for TSV infection on the basis of the high sensitivity of the IQ2000 TSV DPS. RNA prepared from these sam- ples was used as the template for the following NASBA tests. Using analysis by denaturing agarose gel electrophoresis, a single band corresponding to the expected size of 209 nucleotides (Fig. 1A) was detected only from the $\mathrm{TSV}(+)$ shrimp RNA extract, and not from a TSV(-) shrimp RNA extract, yeast tRNA, or $\mathrm{ddH}_{2} \mathrm{O}$. The band was confirmed by Northern blotting using the TSVF3-biotin probe (Fig. 1B) to represent the TSV NASBA amplicons. The specificity of the Northern-blotting analysis was validated by the presence of signals only with the pTSV DNA control, but not with pGFP, a plasmid with unrelated sequences (Fig. 1B).

\section{Dot-blotting analysis of TSV NASBA products}

Based on the Northern-blotting analysis of the TSV NASBA amplicons, no cross-reactive signals could be picked up by the biotin-labeled, TSV-specific primer (Fig. 1B). In order to simplify the detection protocols for the TSV NASBA amplicons, a dot-blotting analysis was developed. The results (Fig. 1C) showed that using the TSV-specific TSVF3-biotin probe, positive signals were obtained only from the NASBA reaction of the TSV(+) RNA and pTSV, the positive control DNA for the detection steps, among the samples tested. In

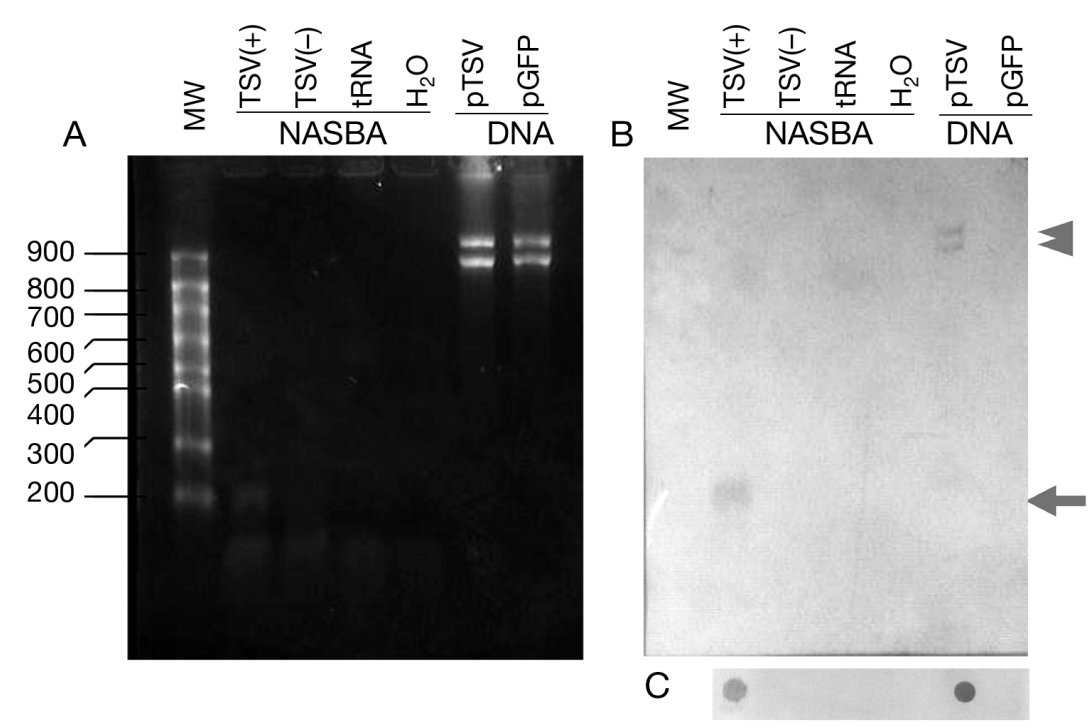

Fig. 1. Gel and Northern-blotting analysis of TSV (Taura syndrome virus) NASBA (isothermal nucleic acid-based amplification) products. Products of the TSV NASBA reactions using primers TSVF2 and T7TSVR2 were separated on (A) a 1.5\% denaturing agarose gel and identified by (B) Northernblotting or (C) dot-blotting analyses using the biotin-labeled detection primer TSVF3-biotin. pTSV and pGFP plasmid DNA were included as positive and negative controls, respectively, for the detection steps (arrow: TSV NASBA product; arrowheads: pTSV; MW: RNA molecular weight markers [bp]; TSV[+]: TSV-positive shrimp RNA; TSV[-]: TSV-negative shrimp RNA; tRNA: yeast tRNA; $\mathrm{H}_{2} \mathrm{O}$ : DEPC-ddH $\mathrm{H}_{2} \mathrm{O}$ ) 
the following experiments, different concentrations of the positive hybridization control, pTSV, were included to ensure that satisfactory degrees of detection sensitivity were reached.

\section{Optimal incubation time for TSV NASBA}

Several conditions for TSV NASBA were varied to optimize its performance. For example, the reaction was stopped after different periods of time and analyzed for the production of TSV NASBA amplicons (Fig. 2). Based on the results, no signals were derived from yeast tRNA and $\mathrm{ddH}_{2} \mathrm{O}$ alone after $120 \mathrm{~min}$. On the other hand, after $30 \mathrm{~min}$ at $41^{\circ} \mathrm{C}$, TSV NASBA produced enough copies of amplicons from the TSV-positive RNA to be vaguely detected by dot blotting. However, the NASBA amplicons could be detected without ambiguity after $50 \mathrm{~min}$ of incubation. The intensity of the signal increased with time, suggesting that the production of NASBA amplicons increases with incubation time between 50 and $120 \mathrm{~min}$ of incubation. Therefore, the NASBA reactions were carried out at $41^{\circ} \mathrm{C}$ for 90 to $120 \mathrm{~min}$ in the following tests.

\section{Comparison of sensitivity between NASBA/dot blotting and RT-nested, PCR-based TSV assays}

To evaluate the feasibility of developing NASBA as an on-site TSV detection platform, the performance of the TSV NASBA/dot-blotting system was compared with a commercially available TSV RT-nested PCR system, the IQ2000 TSV DPS. This system has been applied to routine SPF (specific pathogen-free) broodstock screening at numerous large-scale shrimp farms. First, comparative analysis between the IQ2000 TSV DPS and the OIE TSV RT-PCR detection system, described as one of the standard screening methods for TSV in the 'Manual of diagnostic tests for aquatic animals (OIE 2003), was performed to verify the sensitivity of the IQ2000 TSV DPS. A TSV(+) shrimp RNA was 10 -fold serially diluted and subjected to both assays carried out in parallel. The results showed that the end point of detection was at around a $10^{4}$-fold dilution with the OIE RT-PCR assay (Fig. 3A) and at about a $10^{5}$-fold dilution with the IQ2000 TSV DPS (Fig. 3B), demonstrating that the latter is approximately 10 times more sensitive than the former.

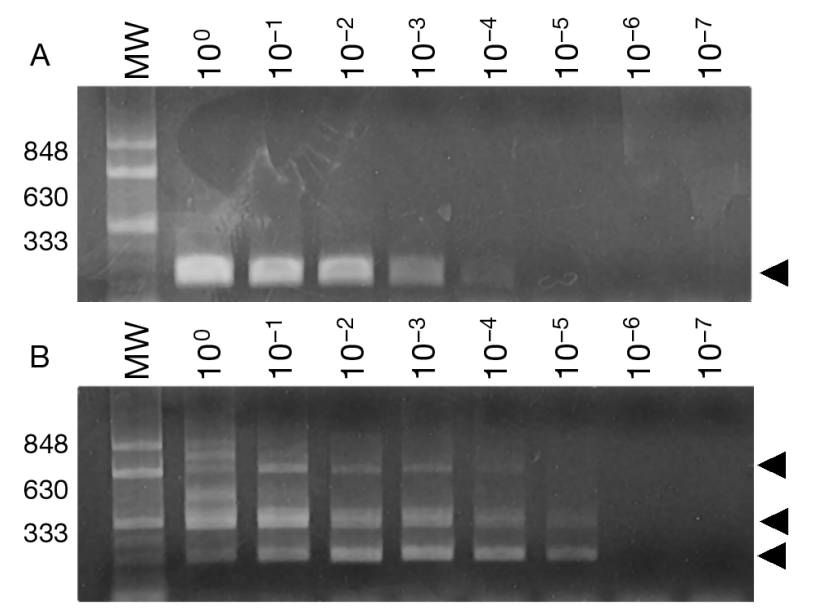

Fig. 3. Comparative sensitivity analysis between OIE (Office International des Epizooties) TSV RT-PCR and IQ2000 TSV DPS assay. A TSV-positive RNA sample prepared from shrimp tissues was 10 -fold serially diluted $\left(10^{0}, 10^{-1}, 10^{-2}\right.$, $10^{-3}, 10^{-4}, 10^{-5}, 10^{-6}$, and $10^{-7}$ ) in yeast tRNA and amplified by either (A) the OIE TSV RT-PCR detection method or (B) the commercially available RT-nested, PCR-based IQ2000 TSV DPS. The PCR products were detected by electrophoresis in a $1.2 \%$ agarose gel (arrowheads: TSV-specific PCR products; MW: DNA molecular weight markers [bp])

With the sensitivity of the IQ2000 system confirmed, we compared the sensitivity of the TSV NASBA established by us side by side with that of the RT-nested PCR-based IQ2000 TSV DPS. A series of 5-fold dilutions of $\mathrm{TSV}(+)$ RNA extract was prepared in a yeast tRNA solution, and the same tRNA was included as the negative control. Replicate analyses were performed. The NASBA/dot-blotting analysis gave significant positive amplicon signals at 6250-fold dilution (Fig. 4A), while the controls worked properly. With the IQ2000 TSV DPS carried out in parallel, amplification of the 


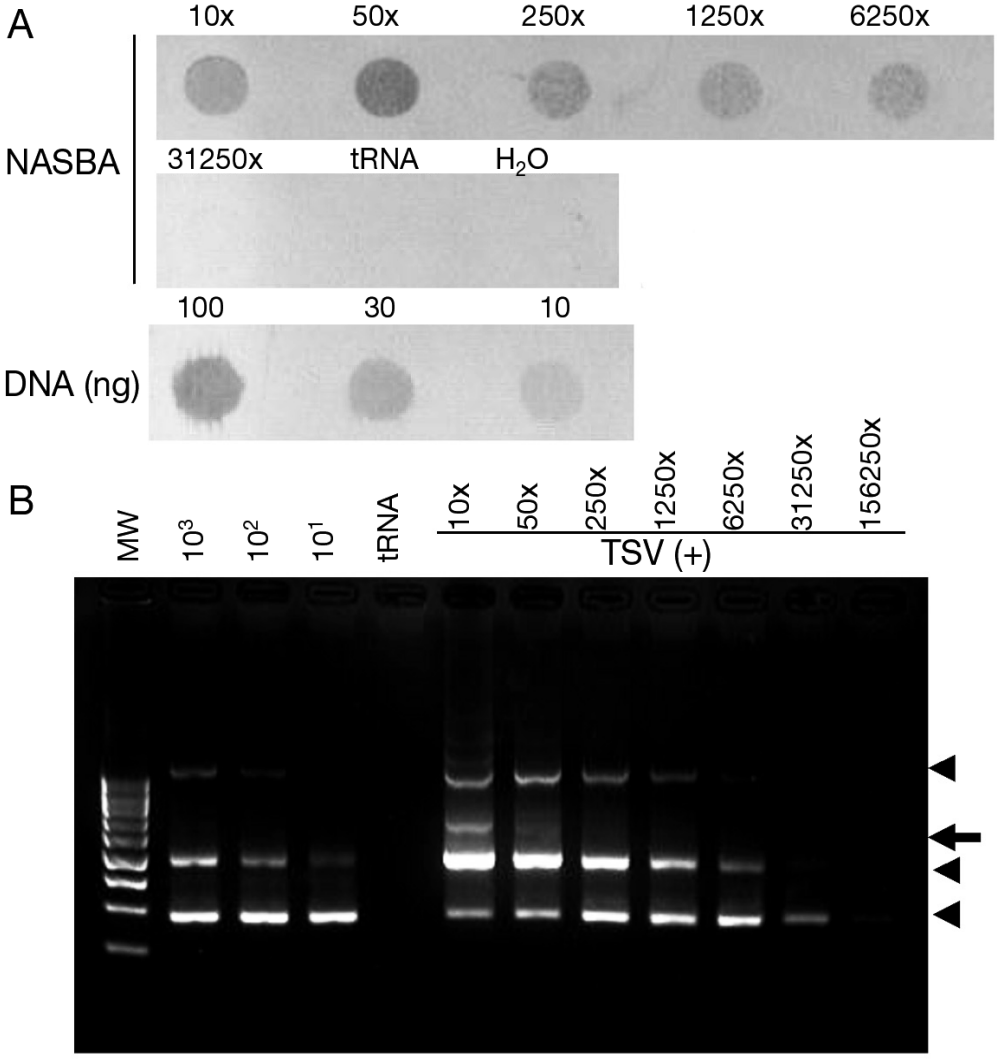

Fig. 4. Comparative sensitivity analysis between TSV NASBA and RTnested, PCR-based IQ2000 TSV DPS reactions. The same RNA extract isolated from a TSV $(+)$ shrimp was 5 -fold serially diluted $(10 \times, 50 \times, 250 \times, 1250 \times$, $31250 \times, 156250 \times$ ) in yeast tRNA and amplified by the NASBA and the RTnested, PCR-based IQ2000 TSV DPS. Both yeast tRNA (tRNA) and DEPC$\mathrm{H}_{2} \mathrm{O}\left(\mathrm{H}_{2} \mathrm{O}\right)$ were included as negative controls. (A) TSV NASBA. NASBA amplicons were analyzed by dot blotting using a biotin-labeled detection probe. pTSV plasmid DNA $(100,30$, and $10 \mathrm{ng})$ was used as a positive control for the detection steps. (B) RT-nested PCR amplification (the IQ2000 TSV DPS). The products were detected by electrophoresis in a $1.2 \%$ agarose gel. The $10^{3}, 10^{2}$, or $10^{1}$ copies of $(+)$ controls were provided by the kit (MW: 100 bp DNA molecular weight markers; arrowheads: TSV-specific PCR products; arrow: internal control signal)
RNA sample were included to monitor the sensitivity of the assays.

\section{Specificity of TSV NASBA}

To further investigate the specificity of the TSV NASBA system, samples positive for several non-target RNA viruses were confirmed to be TSV-negative in advance. Fig. 5B,C shows an example of the screening. In this case, an IMNV(+) sample undiluted or 10 -fold diluted $(1 \times$ or $1 / 10 \times$, respectively) produced IMNV-specific PCR product ladders using the IQ2000 IMNV DPS. The positive controls $\left(2 \times 10^{3}, 2 \times 10^{2}\right.$, and $2 \times 10^{1}$ ) diluted in yeast tRNA gave typical ladders of the IMNV-specific PCR products (Fig. 5B). When the same IMNV(+) sample was subjected to TSV detection by the IQ2000 TSV DPS, only the internal control signals were detected (arrow; Fig. 5C), indicating that the IMNV(+) RNA is TSV negative. Similarly, the YHV(+) and GAV(+) samples were confirmed to be TSV negative (Fig. 5C). When these $\mathrm{YHV}(+), \operatorname{GAV}(+)$, and IMNV(+) RNA extracts were subjected to the TSV NASBA/dot-blotting analysis, no TSV NASBA products were detected (Fig. 5A), demonstrating that the TSV NASBA reaction established is indeed TSV specific.

\section{NASBA detection of TSV in shrimp specimens}

A total of 23 samples from 4 bathes (FITC, CTC, TP, and YS) of Penaeus van- positive controls $\left(10^{3}, 10^{2}\right.$, and $10^{1}$ copies $)$ led to the production of the typical ladders of 1 to $3 \mathrm{TSV}$-specific PCR products (arrowheads; Fig. 4B). Within a 3-log range of target copies, higher amounts of targets would result in the production of more bands. Meanwhile, no products were detected in the negative control reaction (tRNA; Fig. 4B), and the band of around 650 bp (arrow; Fig. 4B) is the RT-PCR internal control signal derived from shrimp RNA. The end point of sample dilution to obtain positive RT-nested PCR signals fell on the 31250 -fold dilution (Fig. 4B), demonstrating that the TSV NASBA assay was about 5-fold less sensitive than the TSV RT-nested PCR assays.

For the subsequent TSV NASBA reactions in this study, serial dilutions of aliquots of the same $\operatorname{TSV}(+)$
Table 2. Analysis of shrimp samples by TSV NASBA/ dot-blotting analysis and the IQ2000 TSV Detection and Diagnosis Kit. Analysis of 4 batches (TC1: Tai-Chung 1; TC2: Tai-Chung 2; TP: Tai-Ping; YS: Yuan-Shin) of TSV samples collected in Taiwan. Different numbers of samples were analyzed concurrently by both the IQ2000 TSV Kit and TSV NASBA/dot-blotting assay

\begin{tabular}{|lccc|}
\hline Batch & $\begin{array}{c}\text { No. of } \\
\text { samples }\end{array}$ & $\begin{array}{c}\text { IQ2000 Kit } \\
\text { positive }\end{array}$ & $\begin{array}{c}\text { TSV NASBA } \\
\text { positive }\end{array}$ \\
\hline TC1 & 5 & $5 / 5$ & $5 / 5$ \\
TC2 & 3 & $3 / 3$ & $3 / 3$ \\
TP & 10 & $2 / 10$ & $1 / 10$ \\
YS & 5 & $5 / 5$ & $4 / 5$ \\
Total & 23 & $15 / 23$ & $13 / 23$ \\
\hline
\end{tabular}



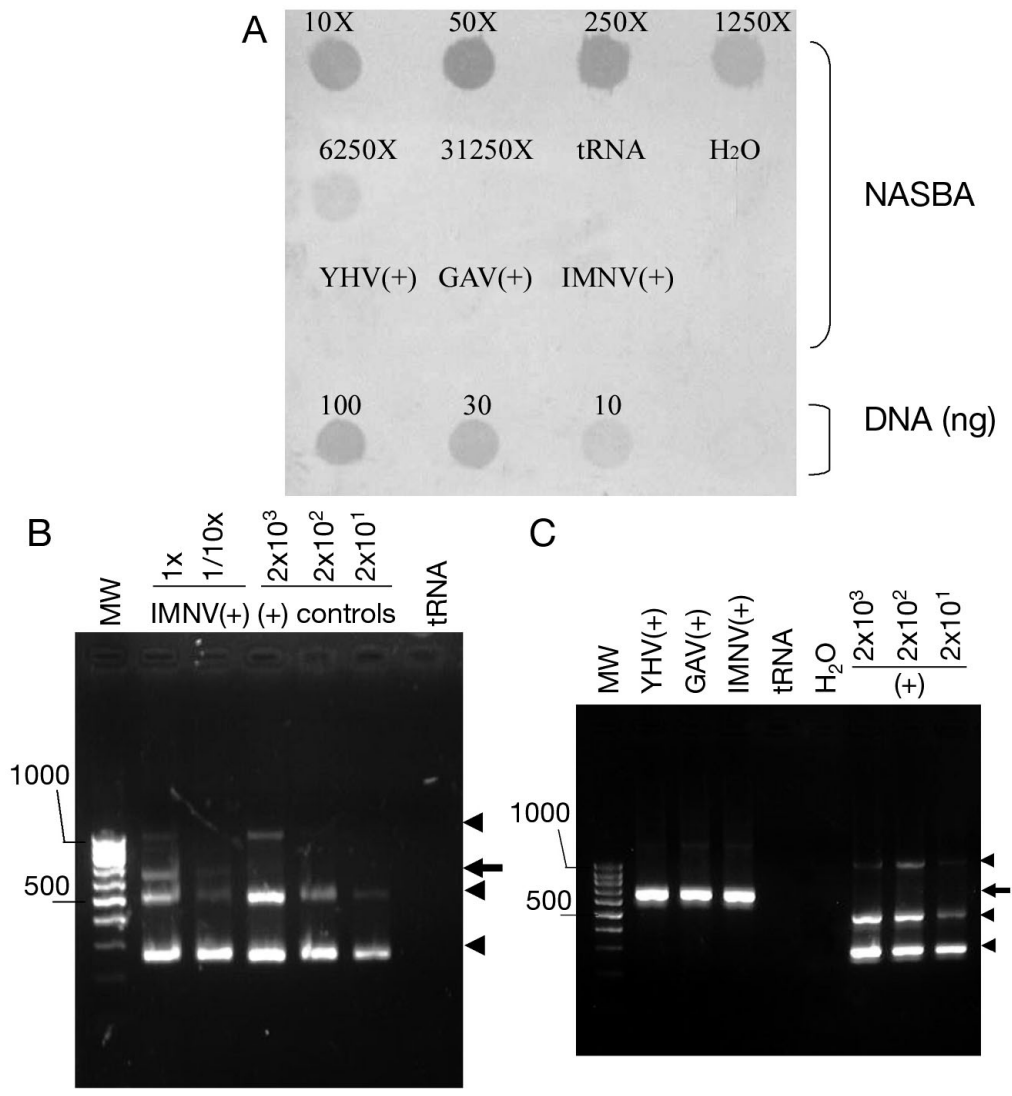

Fig. 5. Specificity of the TSV NASBA reaction. (A) TSV NASBA RNA of $\mathrm{YHV}(+), \operatorname{GAV}(+)$, or IMNV(+) shrimp, together with 10×, 50×, 250×, 1250×, $6250 \times$, or $31250 \times$ dilutions of TSV $(+)$ shrimp RNA, and the negative controls (yeast tRNA and DEPC- $\mathrm{H}_{2} \mathrm{O}$ ) were amplified by TSV NASBA. The pTSV plasmid DNA was included as a positive control for the detection procedures. TSV-specific targets were detected by dot blotting as described in 'Materials and methods'. (B) IMNV RT-nested PCR amplification. The IMNV(+) RNA was identified by using the IQ2000 IMNV DPS. The IMNV(+) RNA, undiluted (1×) or diluted 10-fold (10x), as well as $2 \times 10^{3}, 2 \times 10^{2}$ or $2 \times 10^{1}$ copies of the positive controls provided by the kit were analyzed. The products were analyzed by electrophoresis in a $1.5 \%$ agarose gel, stained with ethidium bromide, and visualized under UV light. (C) TSV RT-nested PCR. The YHV(+), GAV(+), IMNV(+) RNA samples, together with the negative (yeast tRNA and DEPC $-\mathrm{H}_{2} \mathrm{O}$ ) and positive (TSV[+]) controls, were assessed by the IQ2000 TSV DPS (MW: 100 bp DNA molecular weight markers; tRNA: yeast tRNA; arrowheads: virus-specific PCR products; arrows: internal control signal)

namei collected in Taiwan were tested by both TSV NASBA/dot-blotting analysis and IQ2000 TSV DPS (Table 2). In total, 8 of the 23 samples were determined to be TSV negative by both methods. Of the other 15 samples that were diagnosed as TSV positive by the IQ2000 TSV DPS, only 13 were designated as TSV positive by the TSV NASBA/dot-blotting analysis. The 2 samples designated TSV positive by the RT-nested PCR, but TSV negative by TSV NASBA/dot blotting were both categorized by the RT-nested PCR kit as 'weakly infected' (data not shown), i.e. these appeared to be samples with very low virus loads.

\section{End-point detection of TSV by microtiter plate hybridization}

As stated above, solid-phase detection is an attractive platform to be incorporated into a straightforward and cheap diagnostic system (Jean et al. 2002a). Toward this end, the dot-blotting detection protocols were modified and applied to a microtiter plate format, in which NASBA amplicons were detected by a combination of a TSV NASBA ampliconspecific capture probe and a biotinlabeled detection probe. Similarly, positive signals can be visualized by the formation of the purple-colored precipitates. Moreover, a capture probe specific for the biotin-labeled detection probe was fixed on each well (arrows; Fig. 6B) to serve as an internal control for the detection steps. Specific detection of the TSV NASBA RNA amplicons was confirmed by the presence of signals with the $\mathrm{TSV}(+)$ samples and the absence of signals with the GFP RNA produced in vitro (arrowheads; Fig. 6B). Both dot-blotting and microtiter plate detection systems led to positive detection of the TSV NASBA amplicons of the TSV(+) RNA diluted up to 6250-fold (Fig. 6A, B), indicating that these 2 simple systems offer similar degrees of detection sensitivity for the TSV NASBA amplicons.

\section{DISCUSSION}

NASBA is a robust amplification technology that is highly appropriate for RNA analyses and has been applied particularly to detecting various RNA viruses, as well as a number of other pathogens. This report describes the development of a NASBA/solid-phase detection assay for the rapid and sensitive detection of TSV in shrimp tissue specimens. The NASBA reactions were coupled with the simple colorimetric dot-blotting or microtiter plate method for the detection of TSV-specific amplicons (Figs. $1 \& 6$ ). No false-positive results were obtained with yeast tRNA or with non-target shrimp RNA viruses, namely GAV, YHV, or IMNV (Fig. 5), demonstrating a high degree of specificity of the TSV NASBA.

Various formats, including solid-phase hybridization, electrochemiluminescence, molecular beacon, enzymelinked gel assay, and fluorescence correlation spec- 

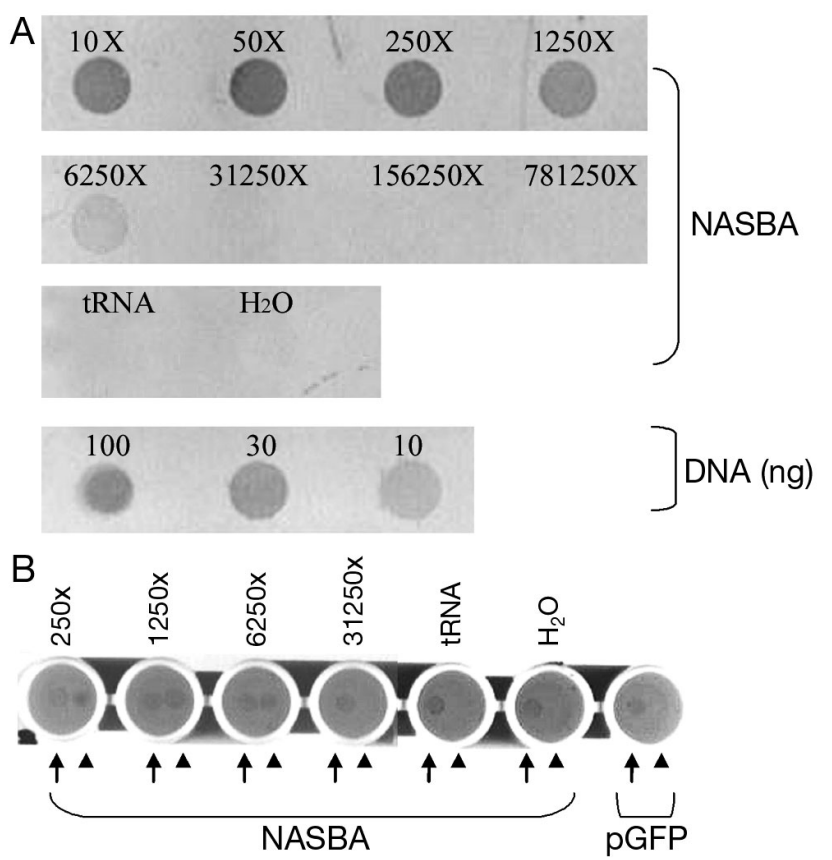

Fig. 6. End-point microtiter plate detection of NASBA amplicons, compared with dot-blotting detection. (A) Dot blotting of NASBA amplicons. NASBA reactions of serial dilutions of the TSV-positive RNA $(10 \times, 50 \times, 250 \times, 1250 \times, 6250 \times, 31250 \times$, $156250 \times, 781250 \times)$, tRNA, and DEPC- $\mathrm{H}_{2} \mathrm{O}$ were spotted on filter paper and detected as described in 'Materials and methods'. The positive pTSV DNA controls $(100,30$, and $10 \mathrm{ng})$ for the hybridization step were also included. (B) Microtiter plate detection of NASBA amplicons. The same NASBA amplicons as those analyzed in (A), together with a negative RNA control (in vitro RNA transcripts of the GFP gene; GFP RNA), were captured by the TSV-specific capture primer (TSVR5; arrowheads) immobilized in each well. The captured NASBA amplicons, in turn, hybridize with the biotin-labeled detection primer and allow subsequent visualization of the signal. The capture primer (TSVR4; arrows) was also immobilized on the well to interact with the biotin-labeled detection primer and thus to serve as a positive control for the detection steps

troscopy have been developed for the detection of NASBA products (Deiman et al. 2002, Jean et al. 2002b). The high costs of equipment, chemicals, and reagents needed to perform real-time assays are prohibitive to the application of most of these formats at shrimp farms. On the other hand, solid-phase hybridization systems, in general, do not require any elaborate tools or expensive apparatus for signal generation, detection, and interpretation. Furthermore, the single-stranded RNA amplicons of NASBA are especially compatible with hybridizationbased detection systems using target-specific probes. To exclude the requirement of any instrument during the detection steps, the colorimetric alkaline phosphatase/ BCIP/ NBT system was adopted, to allow direct visualization of the signals. The dot-blotting system using a TSV-specific, biotin-labeled primer together with the strepavidin-alkaline phosphatase/BCIP/NBT signal amplification system was proven to be efficient for the detection of TSV NASBA products (Figs. 1, 2, 4, \& 5). The sensitivity of the NASBA reaction reproducibly reached the same dilution end point $(6250 \times$ Figs. 5A $\& 6$ ), providing evidence to support the reproducibility of the NASBA method. Moreover, colorimetric microtiter plate detection of NASVA products was later set up and shown to reach a sensitivity similar to that of the dotblotting assay (Fig. 6).

The TSV NASBA assay showed levels of sensitivity comparable to those of the PCR assays (Fig. 4, Table 2). The sensitivity of the TSV NASBA/colorimetric dotblotting method was determined using serial dilutions of TSV(+) RNA extracts prepared from shrimp tissues, and the results were compared against the commercially available RT-nested PCR assay, the IQ2000 TSV DPS, which was demonstrated to be about 10-fold more sensitive than the standard RT-PCR assay, the OIE TSV RT-PCR, as expected (Fig. 3). The detection limits of the TSV NASBA/solid-phase detection system were reproducibly 5-fold less sensitive than the RT-nested PCR assay (Fig. 4). Previously, a NASBA/slot blot detection system using a biotinylated oligonucleotide probe reached detection sensitivity comparable to that of a RT-nested PCR/agarose gel electrophoresis detection system for enterovirus. (Heim \& Schumann 2002, Guichon et al. 2004). Therefore, the sensitivity of the TSV NASBA can likely be improved through further adjustments of either the NASBA reaction or the detection protocols to reach higher levels of sensitivity. To enhance the sensitivity of the solid-phase detection of the NASBA amplicons, other signal amplification methods, such as branched DNA (Tsongalis 2006) or dendrimers (Kim et al. 2003) will be tested.

Results of TSV screening among different batches of shrimp samples by the TSV NASBA and the IQ2000 TSV DPS were in close agreement with each other (Table 2). Thirteen out of 15 TSV RT-nested, PCR-positive samples also tested positive in the TSV NASBA analysis (Table 2). It is likely that levels of TSV RNA in the 2 samples tested negative were below the detection limits of the TSV NASBA, since they were also categorized as 'weakly infected' by the RT-nested PCR assay (data not shown).

Molecular diagnosis of shrimp virus pathogens is particularly important given the difficulty encountered in establishing shrimp cell lines and isolating shrimp viruses from the specimens in tissue culture. Rapid and sensitive detection of TSV can facilitate proper and timely disease management measures to be implemented following the confirmation of TSV cases in the field. Coupling with the end-point solid-phase detection formats described in this study, the TSV NASBA assays can be completed straightforwardly in about 3 to $4 \mathrm{~h}$, meeting the demands for speedy diagnosis of 
aquaculture pathogens at custom and import-control checkpoints and at the farms. The NASBA assay has also been shown to tolerate field contaminants, such as cloacal, pharyngeal, and anal swabs, fecal samples, cage sweepings, and blood, that could interfere with assays, such as ELISA and RT-PCR (Shan et al. 2003), also making it feasible for environmental sampling.

Taken together, the isothermal TSV NASBA/solidphase detection systems have satisfactory sensitivity and specificity, providing an easy and simple approach for TSV detection.

Acknowledgements. This study was funded in part by the National Science Council Grant 93-2622-B-166-006-CC3. We thank Dr. Rong-Fong Lin for technical help.

\section{LITERATURE CITED}

Brock JA (1997) Specific topic review: taura syndrome, a disease important to shrimp farm in the Americas. World J Microbiol Biotechnol 13:415-418

Brown IH (2006) Advances in molecular diagnostics for avian influenza. Dev Biol 124:93-97

Castagna A, Gianotti N, Galli L, Danise A and 5 others (2004) The NIQ of lopinavir is predictive of a 48 -week virological response in highly treatment-experienced HIV-1-infected subjects treated with a lopinavir/ritonavir-containing regimen. Antivir Ther 9:537-543

Chang YS, Peng SE, Yu HT, Liu FC, Wang CH, Lo CF, Kou GH (2004) Genetic and phenotypic variations of isolates of shrimp Taura syndrome virus found in Penaeus monodon and Metapenaeus ensis in Taiwan. J Gen Virol 85: 2963-2968

Cook N (2003) The use of NASBA for the detection of microbial pathogens in food and environmental samples. J Microbiol Methods 53:165-174

Deiman B, van Aarle P, Sillekens P (2002) Characteristics and applications of nucleic acid sequence-based amplification (NASBA). Mol Biotechnol 20:163-179

Demidov VV (2002) Rolling-circle amplification in DNA diagnostics: the power of simplicity. Expert Rev Mol Diagn 2: 542-548

Guichon A, Chiparelli H, Martinez A, Rodriguez C, Trento A, Russi JC, Carballal G (2004) Evaluation of a new NASBA assay for the qualitative detection of hepatitis $\mathrm{C}$ virus based on the NucliSens Basic Kit reagents. J Clin Virol 29: 84-91

Heim A, Schumann J (2002) Development and evaluation of a nucleic acid sequence based amplification (NASBA) protocol for the detection of enterovirus RNA in cerebrospinal fluid samples. J Virol Methods 103:101-107

Hibbitts S, Rahman A, John R, Westmoreland D, Fox JD (2003) Development and evaluation of NucliSens basic kit NASBA for diagnosis of parainfluenza virus infection with 'end-point' and 'real-time' detection. J Virol Methods 108: 145-155

Jean J, Blais B, Darveau A, Fliss I (2002a) Rapid detection of human rotavirus using colorimetric nucleic acid sequence-based amplification (NASBA)-enzyme-linked immunosorbent assay in sewage treatment effluent. FEMS Microbiol Lett 210:143-147

Jean J, Blais B, Darveau A, Fliss I (2002b) Simultaneous detection and identification of hepatitis A virus and rotavirus by multiplex nucleic acid sequence-based amplification (NASBA) and microtiter plate hybridization system. J Virol Methods 105:123-132

Kievits T, van Gemen B, van Strijp D, Schukkink R and 5 others (1991) NASBA isothermal enzymatic in vitro nucleic acid amplification optimized for the diagnosis of HIV-1 infection. J Virol Methods 35:273-286

Kim E, Kim K, Yang H, Kim YT, Kwak J (2003) Enzyme-amplified electrochemical detection of DNA using electrocatalysis of ferrocenyl-tethered dendrimer. Anal Chem 75: 5665-5672

Lambert AJ, Nasci RS, Cropp BC, Martin DA, Rose BC, Russell BJ, Lanciotti RS (2005) Nucleic acid amplification assays for detection of La Crosse virus RNA. J Clin Microbiol 43:1885-1889

Lanciotti RS, Kerst AJ (2001) Nucleic acid sequence-based amplification assays for rapid detection of West Nile and St. Louis encephalitis viruses. J Clin Microbiol 39: 4506-4513

Lightner DV (1995) Taura syndrome: an economically important viral disease impacting the shrimp farming industries of the Americas including the United States. United States Animals Health Association, Reno

Lightner DV (1996) Epizootiology, distribution and the impact on international trade of two penaeid shrimp viruses in the Americas. Rev Sci Tech 15:579-601

Mari J, Bonami JR, Lightner DV (1998) Taura syndrome of penaeid shrimp: cloning of viral genome fragments and development of specific gene probes. Dis Aquat Org 33: $11-17$

Mari J, Poulos BT, Lightner DV, Bonami JR (2002) Shrimp Taura syndrome virus: genomic characterization and similarity with members of the genus Cricket paralysis-like viruses. J Gen Virol 83:915-926

Mayo MA (2002) A summary of taxonomic changes recently approved by ICTV. Arch Virol 147:1655-1663

Nunan LM, Poulos BT, Lightner DV (1998) Reverse transcription polymerase chain reaction (RT-PCR) used for the detection of Taura syndrome virus (TSV) in experimentally infected shrimp. Dis Aquat Org 34:87-91

OIE (Office International des Epizooties) (2003) Manual of diagnostic tests for aquatic animals. Available at: www.oie.int

Overstreet RM, Lightner DV, Hasson KW, McIlwain S, Lotz JM (1997) Susceptibility to Taura syndrome virus of some penaeid shrimp species native to the Gulf of Mexico and the southeastern United States. J Invertebr Pathol 69: $165-176$

Poulos BT, Kibler R, Bradley-Dunlop D, Mohney LL, Lightner DV (1999) Production and use of antibodies for the detection of Taura syndrome virus in penaeid shrimp. Dis Aquat Org 37:99-106

Robles-Sikisaka R, Hasson KW, Garcia DK, Brovont KE, Cleveland KD, Klimpel KR, Dhar AK (2002) Genetic variation and immunohistochemical differences among geographic isolates of Taura syndrome virus of penaeid shrimp. J Gen Virol 83:3123-3130

Romano JW, Shurtliff RN, Sarngadharan MG, Pal R (1995) Detection of HIV-1 infection in vitro using NASBA: an isothermal RNA amplification technique. J Virol Methods 54:109-119

Savan R, Kono T, Itami T, Sakai M (2005) Loop-mediated isothermal amplification: an emerging technology for detection of fish and shellfish pathogens. J Fish Dis 28:573-581

Shan S, Ko LS, Collins RA, Wu Z and 5 others (2003) Comparison of nucleic acid-based detection of avian influenza H5N1 with virus isolation. Biochem Biophys Res Commun 302:377-383 
Starkey WG, Millar RM, Jenkins ME, Ireland JH, Muir KF, Richards RH (2004) Detection of piscine nodaviruses by real-time nucleic acid sequence based amplification (NASBA). Dis Aquat Org 59:93-100

Tai JH, Ewert MS, Belliot G, Glass RI, Monroe SS (2003) Development of a rapid method using nucleic acid sequence-based amplification for the detection of astrovirus. J Virol Methods 110:119-127

Tang KF, Lightner DV (2005) Phylogenetic analysis of Taura syndrome virus isolates collected between 1993 and 2004 and virulence comparison between two isolates representing different genetic variants. Virus Res 112:69-76

Tang KF, Wang J, Lightner DV (2004) Quantitation of Taura

Editorial responsibility: Timothy Flegel,

Bangkok, Thailand syndrome virus by real-time RT-PCR with a TaqMan assay. J Virol Methods 115:109-114

Tsongalis GJ (2006) Branched DNA technology in molecular diagnostics. Am J Clin Pathol 126:448-453

Tu C, Huang HT, Chuang SH, Hsu JP and 5 others (1999) Taura syndrome in Pacific white shrimp Penaeus vannamei cultured in Taiwan. Dis Aquat Org 38:156-161

Yao J, Liu Z, Ko LS, Pan G, Jiang Y (2005) Quantitative detection of HIV-1 RNA using NucliSens EasyQ HIV-1 assay. J Virol Methods 129:40-46

Zhang D, Wu J, Ye F, Feng T, Lee I, Yin B (2006) Amplification of circularizable probes for the detection of target nucleic acids and proteins. Clin Chim Acta 363:61-70

Submitted: April 24, 2006; Accepted: July 17, 2006

Proofs received from author(s): October 30, 2006 